\title{
CIRANDA DE PEDRA, BILDUNGSROMAN DE LYGIA FAGUNDES TELLES
}

\author{
Michaela Pavlovská
}

\begin{abstract}
This article focuses on analysis of the main character Virgínia of the novel The Marble Dance (Ciranda de pedra, 1954) written by Brazilian author Lygia Fagundes Telles (1923) who uses the form of Bildungsroman to show the protagonist's search for her identity. The novel constitutes an alternative to the traditional male novels of formation which contributes to the reformulation of this genre. This way Fagundes Telles introduces a new dynamic heroin who has to gain her "Bildung" on her own and who represents a modern attitude of a female individual toward the world.
\end{abstract}

Keywords: Lygia Fagundes Telles; Bildungsroman; female protagonist; identity.

Resumo: Este artigo tem como objectivo analisar a protagonista do romance Ciranda de pedra (1954) escrito por Lygia Fagundes Telles (1923) que utiliza a forma de "Bildungsroman" para poder focalizar a busca da identidade feminina. O romance constitui uma alternativa aos tradicionais Bildungsromane masculinos, o que contribui para uma redefinição deste género. Assim, Fagundes Telles apresenta uma nova heroína dinâmica que tem de alcançar a sua Bildung sem ajuda dos outros e cujo caminho representa uma nova postura e atitude de um indivíduo feminino em evolução para com a sociedade.

Palavras-chave: Lygia Fagundes Telles; Bildungsroman; a protagonista feminina; identidade.

\author{
Formar a mim mesmo, assim como aqui estou, \\ foi, obscuramente, desde a juventude, \\ o meu desejo. \\ Wilhelm Meister (em Os anos de aprendizagem de \\ Wilhelm Meister de J. W. Goethe)
}

\section{Romance de formação ou seja Bildungsroman}

A utilização do termo "Bildungsroman" remonta já ao princípio do século XIX. Fritz Martini descobriu que o professor Karl von Morgenstern costumava usar esta denominação nas suas aulas e nos seus estudos por volta de 1820, destacando três variações de Bildung: Bildung de protagonista de romance, Bildung interior de escritor e Bildung de leitor, porém, sem uma definição clara deste género, esta designação não se arraigou no mundo literário com firmeza. ${ }^{1}$

\footnotetext{
1 JACOBS, Jürgen - KRAUSE, Markus (1989), Der deutsche Bildungsroman. Gattungsgeschichte vom 18. bis zum 20 Jahrhundert, München: C.H. Beck, p. 22-23.
} 
Somente por meio da obra do filósofo Wilhelm Dilthey este termo foi divulgado no campo académico. Dilthey caracteriza o Bildungsroman como um romance com elementos autobiográficos, mostrando o desenvolvimento de um jovem dentro de determinada cultura e contexto histórico. Segundo o filósofo, este novo género literário representa o "espírito nacional alemão" e os seus ideais.

A ambiguidade da definição deste género romanesco deve-se à polissemia da palavra "Bildung", que para além do significado "criação, formação" (como processo de desenvolvimento) implica não só a significação "erudição, capacitação" (o resultado do processo de desenvolvimento), como também "educação". ${ }^{3}$

Deste modo interpreta o termo Mikhail Bakhtin, que presta atenção ao "problema de romance de formação" no seu livro Estética da criação verbal, ${ }^{4}$ onde se refere à heterogenidade deste género romanesco. $\mathrm{O}$ autor caracteriza Bildungsroman sobretudo através da categoria literária da personagem. A personagem principal torna-se graças à dinámica da sua formação uma "grandeza variável", enquanto na maioria dos romances convencionais, o herói permanece uma "grandeza invariável, constante".

O motivo de desenvolvimento do protagonista desde a infância até à maturidade percebe-se como a pedra mestra de romance de formação. Jürgen Jacobs e Markus Krause ${ }^{5}$ mencionam, como uma outra marca característica, o impulso do protagonista para a sua formação e para a sua tomada de consciência do processo de autoconhecimento. O decurso da formação da personagem costuma ser repleto de complicações e enganos, mas desemboca numa conclusão harmónica. Às experiências típicas de personagem principal pertencem a dissidência com a família, fuga, encontro com a personagem do mestre/ protector, contacto com a arte, actuação duma instituição educacional, primeiras experiências eróticas, escolha da profissão, choque com a vida política e pública.

Jacobs e Krause dedicam-se no seu trabalho somente aos romances de formação alemães desde o século XVIII até ao século XX, analisando os romances mais conhecidos deste género (Agathon de Ch. M. Wieland, Os anos de aprendizagem de Wilhelm Meister de J. W. Goethe, Heinrich von Ofterdingen de Novalis, Titan de J. Paul, Verão tardio de A. Stifter, Henrique o Verde de G. Keller e A montanha mágica de T. Mann), cujos protagonistas são homens. As mulheres no papel de personagem principal ou na função de escritores parecem ser completamente excluídas deste género.

Como cânone do género Bildungsroman é considerado o romance de Goethe Os anos de aprendizagem de Wilhelm Meister, cujos elementos temáticos e estruturais servem como o mais influente paradigma na história do romance alemão. A trajectória de desenvolvimento do protagonista Wilhelm, proveniente duma família burguesa, desejando e buscando uma formação universal, torna-se modelo com o qual numerosas obras intertextualizam, seja pela continuidade, seja pela rejeição.

\section{Romance de formação sob uma perspectiva feminina}

O século XIX introduz uma inovação temática no género de Bildungsroman, sobretudo na literatura inglesa, quer dizer emprega a mulher na função de heroína principal que

\footnotetext{
Ibidem, p. 25-26.

WAHRIG, Gerhard (2001), Deutsches Wörterbuch, München: Bertelsmann Lexikon Verlag, p. 274.

BACHTIN, Michail (1988), Estetika slovesnej tvorby, Bratislava: Tatran.

JACOBS, Jürgen - KRAUSE, Markus (1989), Der deutsche Bildungsroman. Gattungsgeschichte vom 18. bis zum 20. Jahrhundert, München: C.H. Beck, p. 19.
} 
busca o seu lugar na sociedade e deseja com ânsia uma posição equivalente à dos homens. Sem surpresa estes romances foram criados por escritoras (por exemplo J. Austen: Emma,1816, Ch. Brontë: Jane Eyre, 1847), todavia, o seu número foi limitado. ${ }^{6}$

No século XX, com as numerosas mulheres-escritoras, chega a redefinição do género de Bildungsroman. Segundo Cristina Ferreira Pinto, podemos falar do seu "renascimento". A investigadora estabelece no seu livro, intitulado $O$ Bildungsroman feminino: quatro exemplos brasileiros, ${ }^{7}$ um conjunto de motivos que determinam esta especificidade feminina de romance de formação. Entre estes figuram o conflito de gerações (contrariamente ao protagonista masculino, a figura feminina resolve o problema com a mãe, que costuma estar ausente, seja fisicamente ou emocionalmente), a determinação por certa origem social, alienação, aventuras amorosas (os papéis do dominador e do dominante nas relações interpessoais começam a inverter-se), autodidaxia, procura de talento ou capacidades especiais que permitiriam a protagonista afastar-se da sua posição social e experimentar viver independente do mundo masculino (as protagonistas buscam a sua própria identidade, anseiam pelo mais perfeito, por um "eu" independente, mas entretanto os protagonistas realizam a sua mais alta missão) e finalmente, o desfecho do romance, que pode ficar em aberto, eventualmente mostra o fracasso da Bildung feminina (depois de terminar a sua viagem, a personagem masculina integra-se na sua classe social, ficando em harmonia com o mundo circunvizinho, ao contrário, a personagem feminina continua no processo da sua auto-procura ou, na pior das hipóteses, subordinase aos postulados da sociedade que a devora).

\section{Bildungsroman telliano}

Bildungsroman atrai Lygia Fagundes Telles magicamente durante toda a sua criação. Dos seus quatro romances podemos considerar os primeiros dois (Ciranda de pedra, 1954, e Verão no aquário, 1963) como exemplos representativos deste género, o terceiro (As meninas, 1973) contém certos procedimentos e motivos de romance de formação. A esta enumeração poderiamos adicionar também uma novela mais extensa (Confissão de Leontina, 1949, reescrita em 1978), que pode ser denominada, por causa da sua composição e do seu conteúdo, como "Bildungsnovela".

A preferência da autora por este género pode ser explicada pela sua acentuação da função social do escritor, que é percebido como testemunha dos seus tempos, cuja escrita deve captar o espírito da sua época e deve contribuir para a mudança da sociedade. A escritora concentra-se nos seus romances nas situações das mulheres na altura em que a sociedade brasileira passa por transformação e é precisamente este género de romance de formação que lhe permite captar a metamorfose das mulheres limitadas por convenções e tradições em personalidades independentes de forma a poderem elas próprias determinar quem são, o que querem e para onde vão.

O romance Ciranda de pedra (1954) é considerado auge da maturidade artística de L. F. Telles. A própria autora não inclui na sua obra completa nenhuns textos criados antes de 1954, embora se trate de colectâneas de contos apreciados por muitos teóricos literários e reconhecidos por vários prémios. ${ }^{8}$

\footnotetext{
Mocná, Dagmar - Peterka, Josef (2004), Encyklopedie literárních žánrů, Praha-Litomyšl: Paseka, p. 681-683.

7 PINTo, Cristina Ferreira (1990), O Bildungsroman Feminino: Quatro Exemplos Brasileiros, São Paulo: Perspectiva.

8 Trata-se das colectâneas de contos: Porões e sobrados (1938), Praia viva (1944) e O cacto vermelho (1949). Alguns contos foram premiados individualmente e em 1949 a autora recebeu o Prémio Alfonso Arinos pelo o livro de contos $O$ cacto vermelho.
} 
O texto é dividido em duas partes, a narração em er-forma segue uma sequência cronológica que é intercurtada por numerosos monólogos interiores, reflexões, sonhos e lembranças da personagem principal. Na primeira parte, relacionamo-nos com o perfil psicológico da protagonista Virgínia que na sua infância é marcada pela separação dos seus pais. Virgínia mora com a sua mãe Laura, doente mental, e o amante dela, Daniel, que é médico e cuida dela. Este ambiente pesado da casa empobrecida contrasta com o luxo do lugar onde vive o seu pai, Natércio, com as suas irmãs Bruna e Otávia frequentemente acompanhadas por crianças da vizinhança, Conrado, Letícia e Afonso. Virgínia empenha-se em integrar-se no grupo, mas este quinteto não a aceita.

A segunda parte do romance inicia com o regresso de Virgínia, do colégio-internato, ao núcleo de pessoas que a rejeitara quando menina. O grupo outrora fechado e a casa inimiga do pai começam a abrir-se para ela, porém a protagonista descobre, que já é tarde. Virgínia adquire consciência da hipocrisia de todos os chegados, da sua estagnação e incapacidade para mudar a vida estabelecida, por isso, abandona a família e decide tomar o seu rumo próprio.

No romance de Lygia, o Bildungsroman tradicional pode ser visto na transformação complicada da personagem principal, cuja trajectória de menina a mulher jovem é marcada por muitos obstáculos que têm de ser superados.

Até o nome da protagonista, Virgínia, pauta-se por um esquema do romance deste género. O nome leva o significado de "virgem", o que na primeira parte do texto corresponde à pureza psíquica e física da menina. Na segunda parte do romance, o nome da protagonista adquire ainda uma outra dimensão. Apesar de perder a sua castidade, o símbolo de "virgem, virgindade“" não se esvazia totalmente, porque paralelamente contém o sentido de "uma quantia de até então não realizadas possibilidades". . Esta outra camada do símbolo de "virgem" tematicamente encerra o texto. No final do romance, Virgínia encontra-se no início da sua vida independente e livre que se lhe apresenta com muitas novas oportunidades.

Desta maneira, o nome próprio desempenha uma função importante que sublinha o traço do desenvolvimento da personalidade da personagem central e que ecoa a ideia fundamental do Bildungsroman feminino.

Ao contrário de protagonistas masculinos, que estão determinados a expor-se à sua formação, o impulso de Virgínia para o seu desenvolvimento pessoal é o momento de epifania, que vira ao avesso a visão do mundo da protagonista. A epifania da personagem principal acontece no momento, quando descobre, que o pretenso pai, para cuja casa se mudou e por cujo amor esperou, não é o seu pai biológico e que as únicas pessoas que a amavam verdadeiramente, os seus pais reais, estão mortos.

Depois do momento de epifania, o relacionamento da heroína com os pais convertese, porque reconhece o carácter verdadeiro do pai putativo e deixa de se esforçar para cair nas graças dele. Retroactivamente adquire plena consciência das consequências irrefutáveis do seu comportamento, sob influência e manipulação por parte de Bruna.

Embora o momento de iluminação perturbe um pouco a linearidade clássica do Bildungsroman tradicional, não destrói a fluência natural à qual se liga o decorrer do amadurecimento da personagem central.

Um dos elementos do Bildungsroman masculino, que aparece na obra de forma modificada, é a dissidência com os pais. Virgínia na primeira fase da sua formação luta contra

9 BeCKer, Udo (2002), Slovník symbolů, Praha: Portál, p. 301. 
a relação ambivalente com a sua mãe que é psiquicamente perturbada (a protagonista recrimina a dissolução da família à sua mãe, mas ao mesmo tempo admira-a e ama-a), enquanto adora o seu pai Natércio imensuravelmente.

Como Virgínia tem o seu pai verdadeiro, Daniel, na conta do tio que é responsável pela separação dos seus pais, abafa, estimulada pela sua irmã Bruna, o sentimento carinhoso para com ele para não trair Natércio.

O conflito entre a protagonista e os seus pais difere do cânone pela complicada situação familiar (fingimento da parte dos pais), pela enorme emotividade e pelo facto da discordância se tornar o ponto culminante da primeira parte do romance, o que sublinha a importância deste motivo em todo o romance.

Entre a primeira e a segunda parte do romance nasce um abismo temporal no qual desaparecem alguns dos anos que Virgínia passou no colégio-internato. Este facto diferencia esta obra do romance de formação tradicional em que se presta maior atenção ao tempo de educação e formação intelectual. Desta maneira, a autora destaca a importância do desenvolvimento emocional e psíquico durante o processo de autoconhecimento e criação do próprio "eu" independente.

A formação intelectual na forma institucional fica em plano secundário, porém possibilita à protagonista desvincular-se das convenções da classe social à qual pertence, permite-lhe desligar-se do mundo interno, íntimo, que foi determinado para as mulheres, e integrar-se no mundo exterior, público, no mundo dos homens.

No internato, Virgínia confirma a sua competência intelectual, obtendo os melhores resultados de toda a classe, no entanto, oficialmente não é reconhecida como a melhor estudante por causa de ser filha de pais separados. De novo, ela é marginalizada, o que intensifica o seu sentimento de isolamento.

Pela fechada instituição da escola religiosa, enfatiza-se o contraste com a abertura do instituto educacional nos romances de formação masculinos. Esta limitação pelo espaço fechado permeia também as outras fases do desenvolvimento da protagonista. Primeiramente, Virgínia está "aprisionada" na casa da sua mãe, depois na casa do pai, Natércio, seguidamente no internato religioso e de novo na casa paterna.

Ao contrário dos personagens masculinos, cuja esfera privada se transforma na pública, ${ }^{10}$ quer dizer, o mundo abre-se passo a passo a eles, a maioria das figuras femininas criadas na primeira metade do século XX costuma encontrar-se num mundo limitado, somente na esfera privada, íntima. ${ }^{11} \mathrm{Na}$ obra de Lygia as personagens femininas desvinculam-se deste espaço limitado, as mulheres tellianas atravessam as fronteiras estabelecidas pela sociedade. Na fase final da culminância da narrativa, as heroínas encontram-se diante do mundo público que se lhes abre.

$\mathrm{O}$ motivo de instituição educacional pode ser fundido com o motivo da fuga porque Virgínia, graças à sua sensação de alienação, decide distanciar-se da casa de Natércio. Embora não se trate duma excursão ao mundo exterior, a fuga da protagonista para o colégio interno marca o princípio do processo do seu amadurecimento.

Este aspecto não corresponde à concepção tradicional da fuga, que deve levar o protagonista do espaço fechado da família ao espaço aberto do mundo, da mesma maneira que a instituição educacional deve representar um espaço aberto ao mundo.

\footnotetext{
${ }^{10}$ JacoBs, Jürgen - KRAuse, Markus (1989), Der deutsche Bildungsroman. Gattungsgeschichte vom 18. bis zum 20. Jahrhundert, München: C.H. Beck, p. 20-24.

11 PINTO, Cristina Ferreira (1990), O Bildungsroman Feminino: Quatro Exemplos Brasileiros, São Paulo: Perspectiva.
} 
A fuga de Virgínia tem ainda uma outra dimensão, é que ela refugia-se dentro de si, fecha-se em copas, cria o seu próprio mundo interior para poder reviver os momentos com os pais perdidos, para poder entender a sua situação passada e actual e, assim, amortecer as suas emoções revoltadas. No seu isolamento encontra força para se defender do mundo exterior.

É curioso que, embora Virgínia estude numa instituição educacional religiosa, não se aproxima de Deus, não se cinge com a religião, mas, ao contrário, afasta-se dela. Desta forma o seu isolamento torna-se total.

No que diz respeito à personagem do mestre/ protector, este papel não se realiza no romance telliano. Há duas personagens que aspiram ao papel de mentor, quer dizer Daniel, o pai verdadeiro de Virgínia, e Bruna, a irmã mais velha, mas nem um só tem todas as características necessárias.

Daniel transmite a Virgínia o gosto pela literatura e pelo estudo, mas não se esforça pelo papel do seu mestre, sem falar do papel de pai, devido ao seu sentimento de culpa. Daniel desiste dos seus direitos porque não se sente amado pela filha. Escolhe o suicídio como a única saída possível da sua situação. Ausente do decorrer da vida de Virgínia, Daniel não se torna o seu mentor clássico, mas antes o "indicador" da direcção da sua vida. Só retroactivamente, a sua filha descobre todos os traços que a ligam a ele, o que contribui para o seu autoconhecimento.

No caso de Bruna, trata-se da enorme influência na fase infantil quando esta manipula com Virgínia e os seus sentimentos para com a mãe e Daniel. Utilizando citações da Bíblia, Bruna quer persuadir a irmã mais nova da necessidade de condenar o comportamento imperdoável deles e de suportar o traído Natércio. Em vez de ajudar a irmã, Bruna desequilibra a alma dela.

Desta maneira, ainda que criança, Bruna representa uma certa autoridade cuja força influencia o comportamento e pensamento de Virgínia para com à mãe e para com o seu verdadeiro pai e do qual a protagonista mais tarde se virá a arrepender.

A protagonista tem que ganhar a sua Bildung sozinha. Como Virgínia não consegue identificar-se com o mundo circunvizinho, concentra toda a sua energia no desenvolvimento da sua personalidade para adquirir superioridade sobre as proximidades. A relação positiva do protagonista masculino com o seu mestre no Bildungsroman clássico é substituída aqui pela força das circunstâncias negativas que perfilam a personalidade de Virgínia. A heroína de Lygia é forçada a tornar-se mais activa e mais independente do que o protagonista masculino acompanhado pelo seu protector.

As personagens masculinas de Bildungsroman são formadas numa certa fase da sua formação pelo relacionamento com o sexo oposto. As experiências eróticas tematizam-se como instrumentos do poder que os ajudam a fortalecer o seu papel masculino.

Também a nossa protagonista descobre a sua identidade sexual e do mesmo modo que as figuras masculinas, ela a utiliza como seu instrumento de poder (Virgínia consciencializa a sua atracção física, conscientemente coqueteia com o seu cunhado, não se protege da sedução da sua amiga lésbica, flerta com o amante da sua irmã). A personagem principal passa pela transformação do papel de "dominado" para o papel de "dominador", o que a leva a perceber "o jogo social" dentro da ciranda.

Tornando-se "o elemento dominador" nas relações interpessoais, Virgínia adquire plena consciência da força devastadora da sua nova posição que desejou desde menina 
e, por isso, não consegue aproveitá-la inteiramente. Comprendendo que essa mesma força a pode destruir, deixa de "jogar".

Este momento de consciencialização da realidade actual pode ser considerado como o segundo caso de epifania na obra porque influencia a personagem central de modo radical e a ajuda a reencontrar a essência da sua existência.

Ao contrário dos protagonistas masculinos, as experiências eróticas de Virgínia não se viram numa relação harmónica. Nem sequer o seu amor platónico passa a ser real e palpável. Todas as inter-relações entre ela e os homens-amantes fracassam. Ela própria rejeita o amor oferecido porque não quer entrar num relacionamento de dependência.

De novo, a protagonista recusa identificar-se com a concepção tradicional da relação entre mulheres e homens, que poderia colocá-la numa posição de dependência. Prefere escolher uma vida independente que não seja limitada pelo elemento masculino.

O ponto culminante da maturidade masculina é a sua escolha vocacional, que se liga também com as suas actividades e a sua actuação na vida pública e política. A profissão escolhida costuma corresponder à classe social, quer dizer significa prestígio e consolidação da posição da personagem na sociedade. O desfecho harmónico oferece a imagem completa da personagem masculina, cuja personalidade madura se integra ao lado da sua esposa perfeita no mundo circunvizinho.

Virgínia não escolhe a sua profissão, opta por uma viagem que a deve levar a esta escolha. Assim, onde a viagem do protagonista masculino termina, inicia a viagem da personagem central feminina. A sua escolha vocacional não desempenha um papel-chave, o que importa é a sua vontade de procura de possibilidades de realização.

O clímax do romance Ciranda de pedra consiste no facto que Virgínia ganha consciência de si própria, percebe que a sua diligência se adapta, se adequa às exigências do pai Natércio. A protagonista consciencializa que o seu esforço de se integrar no grupo das irmãs e dos seus amigos, custe o que custar, reprimiu o seu verdadeiro "eu". Virgínia decide tomar o caminho longe do lar, o que simboliza outro processo de conhecimento, abertura ao mundo, continuação da sua Bildung. Na comparação com o desfecho harmonioso do clássico Bildungsroman masculino, o desfecho aberto do romance Ciranda de pedra oferece a inesgotável quantia de possibilidades para a seguinte formação da personalidade da protagonista.

Desta comparação das características essenciais referentes à personagem principal do tradicional Bildungsroman masculino com aquelas do romance Ciranda de pedra escrito por Lygia Fafundes Telles, baseando-se sobretudo nas obras teóricas de Jürgen Jacobs, Markus Krause (caracterizando o Bildungsroman masculino) e Cristina Ferreira Pinto (caracterizando o Bildungsroman feminino), decorre que a autora do romance se aproveitou da maioria das marcas características do Bildungsroman tradicional, não na sua forma genuína, mas na modalidade alterada.

O conflito com o pai do Bildungsroman tradicional torna-se em Ciranda de pedra na relação complicada entre a protagonista e a sua mãe que desemboca no conflito com o pai putativo. Desta maneira, o conflito de gerações está tematizado ainda mais intensamente e regista uma nova perspectiva que problematiza esta característica.

Comparando o papel da instituição educacional na trajectória do protagonista masculino e Virgínia, chegamos à conclusão que, quanto ao protagonista, a escola equivale ao "mundo", representando numerosas oportunidades atraentes, entretanto, no caso de 
Virgínia, a instituição educacional simboliza "prisão", que elimina as possibilidades de explorar a vida real.

O motivo de fuga para o mundo exterior que significa abertura para com as novas experiências e, também, independência do lar transforma-se no romance Ciranda de pedra em fuga para dentro de si, quer dizer a protagonista não descobre o mundo circunvizinho mas a si mesma, o que ajuda a aprofundar o processo do seu autoconhecimento.

Como a personagem do mestre desaparece no romance telliano, a protagonista tem que ganhar a sua Bildung sozinha. Assim, a personagem principal é dinamizada e adquire uma dimensão especial que o protagonista masculino não tem, isto é uma atitude activa para com a sua trajectória de desenvolvimento.

No que diz respeito às relações amorosas, a situação difere radicalmente. No Bildungsroman masculino, o casamento corresponde ao sucesso, mas para Virgínia o casamento representa ausência de possibilidade de realização pessoal e fim de crescimento e, por isso, prefere ficar solteira para poder continuar na sua Bildung.

A escolha vocacional considera-se o ponto culminante da maturidade masculina, mas, quanto a Virgínia, não desempenha papel-chave na sua caracterização. A protagonista escolhe a viagem que simboliza o processo de autoconhecimento cujo decorrer passa a ser mais importante do que o seu próprio resultado (a profissão).

Aliás, este facto vincula-se ao desfecho do romance telliano que fica em aberto porque, ao contrário da concluída formação dos protagonistas masculinos, a Bildung de Virgínia continua. Este traço sublinha a importância do processo de autocenhecimento e de busca da identidade feminina.

Assim, Lygia actualiza este género e adapta-o ao mundo contemporâneo. O elemento enovador é, sobretudo, a dinamização e activação da personagem principal feminina que tem que intervir a favor da sua "Bildung ", o que representa uma atitude nova da personalidade de um indivíduo em evolução, interagindo com a sociedade.

\section{Bibliografia}

BACHTIN, Michail (1988), Estetika slovesnej tvorby, Bratislava: Tatran.

BECKER, Udo (2002), Slooník symbolů, Praha: Portál.

JACOBS, Jürgen-KRAUSE, Markus (1989), Derdeutsche Bildungsroman. Gattungsgeschichte vom 18. bis zum 20. Jahrhundert, München: C.H. Beck.

Mocná, Dagmar - Peterka, Josef (2004), Encyklopedie literárních žánrů, PrahaLitomyšl: Paseka.

PINTO, Cristina Ferreira (1990), O Bildungsroman Feminino: Quatro Exemplos Brasileiros, São Paulo: Perspectiva.

Telles, Lygia Fagundes (1981), Ciranda de pedra, Rio de Janeiro: J. Olympio.

WAHRIG, Gerhard (2001), Deutsches Wörterbuch, München: Bertelsmann Lexikon Verlag.

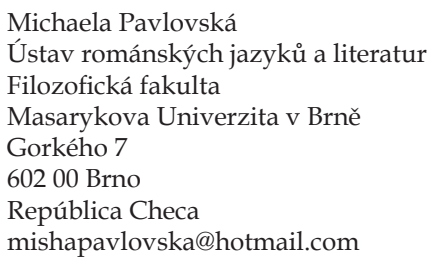

